\title{
Anticoagulation in pulmonary arterial hypertension: a qualitative systematic review
}

\author{
S.R. Johnson*, S. Mehta ${ }^{\#}$ and J.T. Granton
}

ABSTRACT: Thrombotic arteriopathy has been implicated in the pathophysiology of pulmonary arterial hypertension (PAH). However, the role of anticoagulants in the treatment of PAH is uncertain. Through a qualitative systematic review of epidemiological studies, the effectiveness of anticoagulation therapy with warfarin on survival was evaluated in patients with PAH.

MEDLINE (1966 to November 2005), EMBASE (1966 to November 2005), bibliographies of included studies and published reviews were searched without language restriction. Epidemiological studies evaluating the effectiveness of warfarin in PAH were included. Studies had to report mortality as an outcome.

Seven observational studies evaluating the effectiveness of warfarin comprising 488 patients were identified. Five studies support the effectiveness of anticoagulation therapy, whereas two do not.

Data from observational studies suggest that anticoagulation therapy may be an effective intervention in pulmonary arterial hypertension. However, given the methodological limitations and the small number of existing observational studies, a randomised controlled trial is needed in order to definitively address this important clinical issue.

KEYWORDS: Anticoagulation, idiopathic pulmonary arterial hypertension, systematic review, thrombosis, thrombotic arteriopathy, warfarin

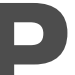
ulmonary hypertension is a devastating condition resulting in significant clinical symptoms, impairment of quality of life and untimely mortality, for which there is currently no cure. Current evidence suggests that abnormalities of blood coagulation factors, antithrombotic factors and the fibrinolytic system contribute to a prothrombotic state in patients with idiopathic pulmonary arterial hypertension (IPAH) [1]. Partly organised vascular thrombosis has been observed in histological studies of IPAH [2]. It has been suggested that the thrombotic pulmonary vascular lesions may be integral aspects of pulmonary vascular remodelling, luminal narrowing and increased vascular resistance, and may contribute to the progression of pulmonary arterial hypertension (PAH).

Given these findings, there may be a role for systemic anticoagulation therapy, with the goals of decreasing the burden of thrombosis and improving outcomes. Many authors have recommended the use of chronic anticoagulation therapy, specifically warfarin, with the intention of improving cardiopulmonary haemodynamics and survival [3-6]. However, these recommendations remain controversial, and there has been a call for further evaluation of the efficacy of anticoagulation therapy in this setting [7], in particular the need for a randomised controlled trial. Through a systematic review of epidemiological studies, the present study synthesises the state of current knowledge regarding the effect of anticoagulation therapy with warfarin on survival in patients with IPAH.

\section{METHODS}

Systematic review of anticoagulation in PAH

Inclusion and exclusion criteria

Eligible studies were published observational studies and randomised controlled trials of human subjects evaluating the use of anticoagulation therapy in IPAH that reported death as an outcome. Studies were ineligible if they included individuals aged $<18$ yrs or with acute/chronic thromboembolic pulmonary hypertension.

Search strategy, methodological assessment and data abstraction

Eligible studies were identified using MEDLINE (1966 to week 1, November 2005; "pulmonary hypertension" plus "warfarin", "Coumadin" or "anticoagulants") and EMBASE (1966 to November

\section{AFFILIATIONS}

*Division of Rheumatology, and -Pulmonary Hypertension Centre, University Health Network, University of Toronto, Toronto, and

\# Southwest Ontario Pulmonary Hypertension Clinic and Centre For Critical IIIness Research, Lawson Health Research Institute, Division of Respirology, London Health Sciences Centre and the Dept of Medicine, University of Western Ontario, London, ON, Canada.

\section{CORRESPONDENCE}

J.T. Granton

Pulmonary Hypertension and Critical Care Medicine

11 NCSB - 1170

Toronto General Hospital

200 Elizabeth Street

Toronto

ON M5G 2C4

Canada

Fax: 14163403359

E-mail: John.Granton@uhn.on.ca

Received:

January 312006

Accepted after revision:

July 052006

\section{SUPPORT STATEMENT}

S.R. Johnson is the recipient of a research fellowship award from the Institute for Musculoskeletal Health and Arthritis, Canadian Institutes of Health Research (Ottawa, ON, Canada) and The Arthritis Society (Toronto, ON, Canada). No financial or other potential conflicts of interest exist for J.T. Granton and S. Mehta. 
2005; same search) without language restriction. Titles and abstracts were screened to exclude ineligible studies. Included studies were entered into PUBMED and the "related articles" tool was used to search for other potentially eligible studies. The bibliographies of included studies and published reviews were also searched. Two reviewers independently abstracted the following data on to standardised forms: study design, patient sample size, aetiology, treatments, and 3- and 5-yr mortality data. The reviewers were blinded to the names of authors, institutions and journals when performing data abstraction. All disagreements were resolved by consensus.

\section{RESULTS}

Of the 737 studies identified through a systematic review of the literature, nine observational studies were identified for full review. No randomised controlled trials were identified. One study evaluated the effect of the anticoagulant fraxiparin in patients with IPAH; however, it was excluded as it did not evaluate the end-points of interest [8]. Another study was excluded as it reported duplicate data (fig. 1) [9]. One study reported outcomes in both IPAH and PAH associated with other diseases or things (APAH), in this case anorexigens. Since mortality data were available for the IPAH subset, this study was included in the present review. The remaining studies, comprising 488 patients, are summarised in table 1.

Five studies support the effectiveness of warfarin with regards to survival in IPAH. ROMAN et al. [14] reported a retrospective case series of 44 IPAH patients followed in Barcelona (Spain) during the period 1992-2000. The mean (range) systolic pulmonary arterial pressure $(P \mathrm{pa})$ of the cohort was $92 \mathrm{mmHg}$ (43-154). The investigators reported that five patients improved with warfarin and calcium channel blocker (CCB) therapy (diltiazem or nifedipine) [14].

FUSTER et al. [11] reported upon a retrospective cohort of patients diagnosed with IPAH at the Mayo clinic during the period 1955-1977, and followed until 1983 (median follow-up $14 \mathrm{yrs}$ ). The mean age at study entry was $34 \mathrm{yrs}$, and 73\% were

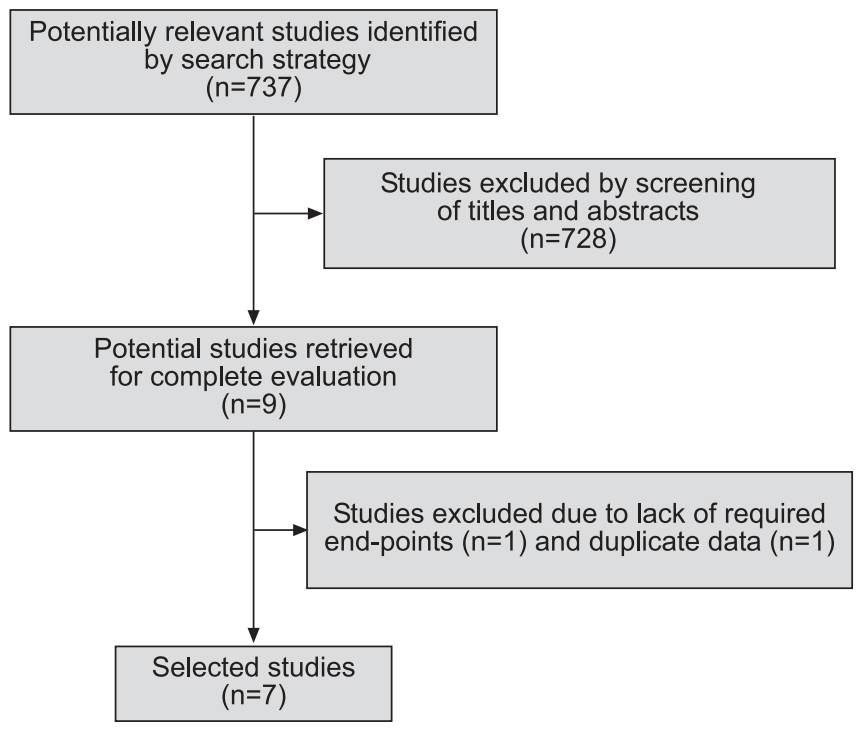

FIGURE 1. Flow diagram showing systematic review protocol. female. In these patients, many of whom showed severe PAH (mean (range) Ppa $64 \mathrm{mmHg}(36-120)$ ), 57\% showed evidence of chronic organised pulmonary vascular thromboses on autopsy. Exposure to anticoagulation therapy was defined as initiation of warfarin treatment within 12 months of diagnosis. No other PAH-specific therapies were reported. The median (range) time to death from diagnosis was 1.9 yrs (0-16). Although overall survival was poor (only $21 \%$ of patients survived 5 yrs), improved 3-yr survival was observed in 78 patients who had received anticoagulant therapy compared with 37 who had not $(\mathrm{p}=0.02)$. Univariate analysis of the 56 patients who underwent autopsy demonstrated a beneficial effect of anticoagulant therapy $(p=0.04)$. In a stepwise multivariate analysis, one of the strongest positive prognostic factors was the use of systemic anticoagulation therapy $(p=0.01)$.

In a third study, OGATA et al. [13] reported a Japanese retrospective cohort study of seven IPAH patients treated with warfarin in conjunction with a vasodilator (isoproterenol 30-45 mg daily or nifedipine 30-40 mg daily), and compared their outcome to that of $13 \mathrm{IPAH}$ patients who were not treated. The warfarin dose was titrated to maintain thrombo test results within the range of $10-25 \%$. Treatment duration was not specified. The mean (range) age at diagnosis was 31.2 yrs (14-56), and 50\% of patients were in New York Heart Association Functional Classes II or III. The age at diagnosis was higher in the treatment group than in the control group $(39 \pm 15.5$ versus $27.2 \pm 12.0$ yrs; $\mathrm{p}<0.05)$; however, there was no difference between groups in terms of duration of symptoms or functional class. Despite similar baseline haemodynamics (baseline mean $P$ pa was $57.5 \pm 8.9$ versus $49.3 \pm 5.0 \mathrm{mmHg}$ in the treatment and control groups, respectively), the treatment group showed a reduction in $P$ pa of $19 \pm 14 \%(p<0.05)$ and a reduction in pulmonary vascular resistance of $13 \pm 17 \%$ $(p<0.05)$. Five-year survival was improved in the treatment group compared with controls (57 versus $15 \%$; $\mathrm{p}<0.025$ ).

In a prospective cohort study, RICH et al. [15] evaluated the effectiveness of CCBs in IPAH patients referred to the University of Illinois between July 1985 and March 1991, and followed until October 1991. Co-interventions included digoxin (for all CCB recipients), diuretics (for patients with a history of pedal oedema or right atrial pressure of $>8 \mathrm{mmHg}$ ) and warfarin (for patients with nonuniform blood flow on nuclear lung perfusion scan). In all, 35 of 64 (55\%) patients with IPAH received warfarin. Survival, adjusted for baseline haemodynamic variables and response to CCBs, was better in those treated with warfarin than in those not treated with warfarin $(p=0.025)$. In a post hoc subgroup analysis, there was no significant difference in survival in vasodilator responder patients treated or not treated with anticoagulation therapy. This improvement in survival was found in patients not receiving chronic CCB therapy over the 5-yr follow-up period because of the lack of an acute CCB vasodilator response. In this group of patients, the survival rates at 1, 3 and 5 yrs were 91, 62 and $47 \%$, respectively, with anticoagulation therapy versus 52, 31 and $31 \%$, respectively, without anticoagulation therapy.

Finally, in a recent retrospective cohort study, KAWUT et al. [12] evaluated predictors of outcome in IPAH patients. They evaluated 84 consecutive newly diagnosed adult PAH patients 
TABLE 1 Observational studies of anticoagulant therapy in idiopathic pulmonary arterial hypertension

\begin{tabular}{|c|c|c|c|c|}
\hline First author [ref.] & Study design & Subjects $n$ & Exposure & Outcomes \\
\hline Frank [10] & Retrospective cohort & 69 & Warfarin & $\begin{array}{c}\text { No difference in } 5 \text {-yr survival; nonsignificant survival benefit in } \\
\text { warfarin-treated group at } 10 \mathrm{yrs}\end{array}$ \\
\hline Fuster [11] & Retrospective cohort & 115 & Warfarin & $\begin{array}{l}\text { Improved 3-yr survival in } 78 \text { anticoagulant- versus } 37 \\
\text { nonanticoagulant-treated patients }(p=0.02)\end{array}$ \\
\hline KaWUT [12] & Retrospective cohort & 66 & Warfarin & $\begin{array}{l}\text { Improved transplant-free survival; HR } 0.35 \\
\qquad(95 \% \mathrm{Cl} 0.12-0.99 ; \mathrm{p}=0.05)\end{array}$ \\
\hline Roman [14] & Case series & 44 & Warfarin & Improvement in five patients \\
\hline RICH [15] & Prospective cohort & 35 & Warfarin & $\begin{array}{l}\text { Improved survival in subgroup of patients treated with warfarin } \\
\text { compared to nonanticoagulant-treated patients }(p=0.025)\end{array}$ \\
\hline Storstein [16] & Retrospective cohort & 10 & Anticoagulant ${ }^{\#}$ & $\begin{array}{l}\text { No difference in survival between anticoagulant- and } \\
\text { non-anticoagulant-treated patients }\end{array}$ \\
\hline
\end{tabular}

between January 1994 and June 2002. Eighty-four patients were included in the study, of whom $66(78 \%)$ had IPAH. Of the remainder, $14(17 \%)$ had familial PAH and four $(5 \%)$ anorexigen-associated APAH. Sixty-eight $(81 \%)$ were female. The cohort had a mean age of $42 \pm 14$ yrs and mean (range) $P$ pa of $55 \mathrm{mmHg}$ (48-61). Seventy-nine (86\%) patients were treated with warfarin. Multivariate analyses of transplant-free survival indicated that warfarin use was associated with survival (hazard ratio 0.35, 95\% confidence interval (CI) 0.12-0.99; $\mathrm{p}=0.05)$.

In contrast to the previous studies, two observational studies did not support the effectiveness of anticoagulation therapy in IPAH. STORSTEIN et al. [16] reported a retrospective cohort study of $10 \mathrm{IPAH}$ patients treated with anticoagulants and seven not treated with anticoagulants over a 6-yr period. The age of the patients ranged 7-70 yrs and the disease duration ranged 1-22 yrs. Symptom severity ranged from slight dyspnoea on exertion to dyspnoea at rest. Four patients reported a previous history of thrombosis. The baseline mean systolic $P$ pa on cardiac catheterisation ranged $50-125 \mathrm{mmHg}$. Treatment with anticoagulants (type not specified) was titrated to maintain a prothrombin-proconvertin time in the range of $10-30 \%$. Treatment duration ranged $2-5$ yrs. No other PAHspecific medical therapies were described. Of the nine patients who underwent pathological evaluation, four showed pulmonary artery thrombosis in conjunction with arteriopathic changes. Follow-up cardiac catheterisation was performed in four of the anticoagulant-treated patients, and none exhibited a reduction in their Ppa during treatment. Six anticoagulanttreated patients died during the study period. The investigators concluded that anticoagulation therapy provided neither a reduction in $P$ pa on cardiac catheterisation nor a difference in survival between groups [16].

In a retrospective cohort study, FRANK et al. [10] evaluated the effectiveness of warfarin on survival, $P$ pa and New York Heart Association Functional Class in 173 patients with IPAH or aminorex-associated APAH in Vienna (Austria) and Bern (Switzerland). The nonanticoagulant-treated IPAH group consisted of 45 patients ( 36 female and nine male). There were 24 anticoagulant-treated IPAH patients (17 female and seven male), with a mean age of $44 \pm 11.7$ yrs. Among the patients exposed to warfarin, seven were treated immediately after diagnosis, six had their therapy initiated within $1 \mathrm{yr}$ of symptom onset and four within 2 yrs. Co-interventions in both the warfarin-exposed and -nonexposed IPAH and APAH groups included digoxin, diuretics, steroids and $\alpha$-adrenergic receptor antagonists. The investigators reported improved 5- (63 versus $38 \%$ ) and $10-y$ r survival (39 versus $20 \%$ ) in warfarin-treated versus warfarin-naive APAH patients. However, no difference in 5-yr survival was observed between warfarin-treated and warfarin-naive IPAH patients. A nonsignificant survival benefit was observed in the warfarintreated group at 10 yrs [10].

\section{DISCUSSION}

The effect of anticoagulation therapy on survival in patients with PAH has long been controversial. To the present authors' knowledge, this is the first qualitative systematic review in the literature examining this issue. A previous pathophysiological review identified several lines of evidence to suggest a relationship between thrombotic arteriopathy and PAH [1]. Abnormalities of the activated clotting system [17-19], impaired fibrinolysis [20, 21], abnormal platelet function [22, 23] and histological evidence of microvascular thrombosis [24, 25] have been associated with animal models and patients with IPAH. Thus, there is a biologically plausible rationale for anticoagulation therapy in these patients, with the goals of preventing progression of disease, decreasing $P$ pa, and improving symptoms and prognosis [1]. However, initial case reports and case series reported conflicting outcomes with regards to the effectiveness of anticoagulation therapy on survival [26-28]. Through the present systematic review, seven observational studies addressing the effectiveness of anticoagulant therapy on survival were identified. One recent case series [14], three retrospective cohort studies [11, 12, 13] and one prospective cohort study [15] have demonstrated a survival benefit of anticoagulation therapy in IPAH patients. 
Improved 5-yr (63 versus 38\%) and 10-yr survival (39 versus $20 \%$ ) has been reported in warfarin-treated versus warfarinnaive APAH patients [10]. However, two retrospective cohort studies did not corroborate this finding $[10,16]$.

Overall, the literature supports a treatment effect of warfarin on survival in IPAH patients. These results suggest that interruption of ongoing thrombosis with effective systemic anticoagulation therapy is associated with a better prognosis, especially for patients with disease not responsive to vasodilators. The available data were insufficient for a formal metaanalysis, and the present results should be interpreted with caution. Many of the studies evaluated patient groups that were heterogeneous with regards to a number of important factors, including age, study location, inclusion of paediatric patients, disease duration and treatment duration. Furthermore, these factors were often not accounted for in the analyses. Due to the heterogeneity of study designs and study populations, pooling the data of these observational studies in a meta-analysis would be inappropriate [29].

A number of methodological concerns affect the validity of the study results. Earlier studies may have suffered from misclassification bias, as they were unable to accurately distinguish IPAH from other causes of PAH. In addition, selection bias and confounding by severity threaten the validity of some of these studies. Many of the studies did not identify how patients were selected for participation in the study. Many studies did not indicate on what basis anticoagulation therapy was given to some patients, and, conversely, on what basis it was withheld from others.

Confounding by severity occurs when the severity of the disease systematically influences exposure. Sicker patients, or those with increased bleeding risk, may not have been prescribed warfarin, and, as a result, the cohort studies may show better outcomes in those patients treated with warfarin therapy, whereas, in reality, this is just a reflection of the fact that sicker patients with a higher risk of death were not given warfarin.

Inconsistencies regarding treatment exposure and use of cointerventions also threaten the validity of the results. Exposure to warfarin was not consistently specified across studies. One study did not clearly identify what type of anticoagulant(s) were used, whereas others did not clearly state whether all patients in the study received the same form of anticoagulation therapy. Finally, the use of co-intervention(s) was not accounted for in the estimates of treatment effect. For example, in the study of OGATA et al. [13], survival was improved in patients treated with oral anticoagulant therapy in combination with vasodilators (isoproterenol or nifedipine). However, acute vasoreactivity was not reported in these patients. The effect on survival may be related to vasodilator rather than anticoagulation therapy if some of these patients were considered acute responders. Due to the effects of confounding and bias, these observational studies (individually and together) may produce estimates of associations that deviate from the underlying effect in ways that may systematically differ from chance.

These studies provide insufficient data to form conclusions about the appropriate dose of warfarin. The American College of Chest Physicians Clinical Practice Guidelines recommend a target international normalised ratio (INR) of 1.5-2.5 [4]. Additional research is needed to evaluate the validity of this therapeutic range.

It is also important to recognise that anticoagulation therapy using warfarin is not without potential risk. The greatest concern pertains to the risk of major haemorrhage, including gastrointestinal bleeding and intracranial haemorrhage. The risk of these complications in warfarin-treated $\mathrm{PAH}$ patients is uncertain. However, large studies of patients treated with warfarin for venous thrombosis or atrial fibrillation reported annual incidence estimates for major haemorrhage of $2-3 \%$ [30, 31]. The risk of major haemorrhage increases with advanced age, concomitant renal, cardiac and hepatic disease, and diabetes [30-33]. There is also concern regarding increased risk of gastrointestinal haemorrhage among patients with scleroderma-associated pulmonary hypertension due to the presence of luminal telangiectasia [34]. Many medications have been implicated in potentiation of the effect of warfarin, including azole antibiotics [35, 36], macrolides [37], quinolones [38], selective serotonin reuptake inhibitors [39] and amiodarone [40-42]. Caution should also be exercised with the concomitant use of other $\mathrm{PH}$ therapies and warfarin. MURPHEY and HOOD [43] have suggested that bosentan may decrease the anticoagulant properties of warfarin, whereas WIDLITZ et al. [44] report an increased prothrombin time/INR in patients taking warfarin and sitaxsentan, requiring significant warfarin dose reduction. OGAWA et al. [45] have reported an increased risk of alveolar haemorrhage in patients taking epoprostenol and warfarin. The medications of most concern are those with an inherent risk of bleeding, which further potentiates the risk of haemorrhage with warfarin and attendant monitoring of the INR is not helpful. These include antiplatelet agents and both cyclooxygenase-2selective and -nonselective nonsteroidal anti-inflammatory drugs. Combination of these drugs with warfarin should be monitored closely [46].

In addition, there is increasing evidence that a therapeutic INR range is difficult to maintain in the long term. In a large population-based cohort study of patients with atrial fibrillation and treated with warfarin, patients were outside the INR target range $32.1 \%$ of the time, with $15.4 \%$ of INRs being $>3.0$ [47]. Similarly, in a meta-analysis evaluating the relationship between the INR and major bleeding events among atrial fibrillation patients receiving warfarin, REYNOLDS et al. [48] reported that patients spent $13 \%$ of the time in the supratherapeutic range. Furthermore, an INR of $>3.0$, compared with an INR of $\leqslant 3.0$, was associated with an odds ratio of 3.21 (95\% CI 1.24-8.28) for bleeding events. Further research is needed to evaluate whether or not these observations hold true for PAH patients treated with warfarin.

In summary, five observational studies suggest that there is a survival benefit associated with warfarin in the treatment of IPAH, whereas two observational studies do not support this association. As epidemiological studies, these cohort studies suffer from many methodological issues, including selection bias and confounding by indication. The impossibility of accounting for all measured and unmeasured confounding factors in such studies means that conclusions must be 
tempered in the absence of a randomised clinical trial. There remains clinical uncertainty regarding the effect of anticoagulation therapy on survival patients with IPAH.

Furthermore, anticoagulation therapy with warfarin is associated with inherent risks.

In order to definitively evaluate the efficacy of anticoagulation therapy with warfarin on survival and ascertain whether or not the clinical benefit outweighs the potential risks, a randomised controlled trial is needed. Proposals for randomised trials to evaluate the efficacy of warfarin in IPAH and sclerodermaassociated PAH patients have been developed in both the USA (D. Badesch, Pulmonary Hypertension Center, University of Colorado Health Sciences Center, Denver, CO, USA, personal communication (September 2005)) and Canada (J. Granton, Pulmonary Hypertension Programme, University Health Network, University of Toronto, Toronto, ON, Canada, personal communication (February 2004)). Undoubtedly, clinical trials of rare diseases suffer from many methodological challenges. First is the issue of recruitment of adequate numbers of patients so that there is sufficient power to detect meaningful treatment effects. The second challenge is the fact that one arm may deteriorate faster than another. One innovative design and analytical strategy that may be useful is Bayesian inference. Bayesian inference allows for the reporting of a probability of a treatment effect using the available data [49]. Study data could be analysed in a Bayesian context during interim analyses and inform decision rules for early termination of the study [50]. In this way, fewer patients are needed to address clinically meaningful outcomes. Clinical deterioration would be detected using conventional endpoints, such as 6-min walking distance, functional class and time to clinical worsening. A multidisciplinary group of investigators is currently using consensus methods to identify appropriate outcome measures for clinical trials of scleroderma-associated PAH (D. Pittrow, Dept for Clinical Pharmacology, Medical Faculty, Technical University of Dresden, Dresden, Germany, personal communication (February 2006)). Similar research is required to identify appropriate outcome measures for clinical trials of IPAH. Together, the results of these trials will clarify this important issue.

\section{Conclusion}

The literature appears to support a treatment effect of anticoagulation therapy with warfarin on mortality in idiopathic pulmonary arterial hypertension. However, conflicting results and methodological issues regarding previous observational studies demonstrate the need for a randomised controlled trial in order to definitively evaluate the efficacy of warfarin in pulmonary arterial hypertension patients.

\section{REFERENCES}

1 Johnson SR, Granton JT, Mehta S. Thrombotic arteriopathy and anticoagulation in pulmonary hypertension. Chest 2006; 130: 545-552.

2 Moser KM, Fedullo PF, Finkbeiner WE, Golden J. Do patients with primary pulmonary hypertension develop extensive central thrombi? Circulation 1995; 91: 741-745.
3 Dincer H, Presberg K. Current management of pulmonary hypertension. Clin Pulm Med 2004; 11: 40-53.

4 Badesch DB, Abman SH, Ahearn GS, et al. Medical therapy for pulmonary arterial hypertension: ACCP evidencebased clinical practice guidelines. Chest 2004; 126: Suppl. 1, 35S-62S.

5 Humbert M, Sitbon O, Simonneau G. Treatment of pulmonary arterial hypertension. N Engl J Med 2004; 351: 1425-1436.

6 Rubin LJ, Badesch DB. Evaluation and management of the patient with pulmonary arterial hypertension. Ann Intern Med 2005; 143: 282-292.

7 Newman JH, Fanburg BL, Archer SL, et al. Pulmonary arterial hypertension: future directions: report of a National Heart, Lung and Blood Institute/Office of Rare Diseases workshop. Circulation 2004; 109: 2947-2952.

8 Chazova IE, Panchenko EP, Dobrovol'skii AB, et al. [The effect of long-term Fraxiparin treatment on haemostasis in patients with primary pulmonary hypertension]. Ter Arkh 1997; 69: 62-66.

9 Frank H, Gurtner HP, Kneussl M, Lang I, Mlczoch J. Aminorex-induzierte, plexogene pulmonale Arteriopathie: 25 Jahre danach! [Aminorex-induced, plexogenic pulmonary arteriopathy: 25 years later!]. Z Kardiol 1993; 82: 568-572.

10 Frank H, Mlczoch J, Huber K, Schuster E, Gurtner HP, Kneussl M. The effect of anticoagulant therapy in primary and anorectic drug-induced pulmonary hypertension. Chest 1997; 112: 714-721.

11 Fuster V, Steele PM, Edwards WD, Gersh BJ, McGoon MD, Frye RL. Primary pulmonary hypertension: natural history and the importance of thrombosis. Circulation 1984; 70: 580-587.

12 Kawut SM, Horn EM, Berekashvili KK, et al. New predictors of outcome in idiopathic pulmonary arterial hypertension. Am J Cardiol 2005; 95: 199-203.

13 Ogata M, Ohe M, Shirato K, Takishima T. Effects of a combination therapy of anticoagulant and vasodilator on the long-term prognosis of primary pulmonary hypertension. Jpn Circ J 1993; 57: 63-69.

14 Roman A, Rodes-Cabau J, Lara B, et al. Estudio clinicohemodinamico y tratamiento de 44 pacientes con hipertension pulmonar primaria. [Clinico-haemodynamic study and treatment of 44 patients with primary pulmonary hypertension]. Med Clin (Barc) 2002; 118: 761-766.

15 Rich S, Kaufmann E, Levy PS. The effect of high doses of calcium-channel blockers on survival in primary pulmonary hypertension. $N$ Engl J Med 1992; 327: 76-81.

16 Storstein O, Efskind L, Muller C, Rokseth R, Sander S. Primary pulmonary hypertension with emphasis on its etiology and treatment. Acta Med Scand 1966; 179: 197-212.

17 Geggel RL, Carvalho AC, Hoyer LW, Reid LM. von Willebrand factor abnormalities in primary pulmonary hypertension. Am Rev Respir Dis 1987; 135: 294-299.

18 Lopes AA, Maeda NY. Circulating von Willebrand factor antigen as a predictor of short-term prognosis in pulmonary hypertension. Chest 1998; 114: 1276-1282.

19 Lopes AA, Maeda NY, Aiello VD, Ebaid M, Bydlowski SP. Abnormal multimeric and oligomeric composition is associated with enhanced endothelial expression of von 
Willebrand factor in pulmonary hypertension. Chest 1993; 104: 1455-1460.

20 Eisenberg PR, Lucore C, Kaufman L, Sobel BE, Jaffe AS, Rich S. Fibrinopeptide A levels indicative of pulmonary vascular thrombosis in patients with primary pulmonary hypertension. Circulation 1990; 82: 841-847.

21 Langleben D, Moroz LA, McGregor M, Lisbona R. Decreased half-life of fibrinogen in primary pulmonary hypertension. Thromb Res 1985; 40: 577-580.

22 Christman BW, McPherson CD, Newman JH, et al. An imbalance between the excretion of thromboxane and prostacyclin metabolites in pulmonary hypertension. N Engl J Med 1992; 327: 70-75.

23 Kanai Y, Hori S, Tanaka T, et al. Role of 5-hydroxytryptamine in the progression of monocrotaline induced pulmonary hypertension in rats. Cardiovasc Res 1993; 27: 1619-1623.

24 Wagenvoort CA. Lung biopsy specimens in the evaluation of pulmonary vascular disease. Chest 1980; 77: 614-625.

25 Bjornsson J, Edwards WD. Primary pulmonary hypertension: a histopathologic study of 80 cases. Mayo Clin Proc 1985; 60: 16-25.

26 Davison P, Armitage G, Mcllveen D. Chronic cor pulmonale due to silent pulmonary embolism. Lancet 1956; 271: 224-226.

27 Wilcken D, Mackenzie K, Goodwin J. Anticoagulant treatment of obliterative pulmonary hypertension. Lancet 1960; 2: 781-783.

28 Goodwin J, Harrison C, Wilcken D. Obliterative pulmonary hypertension and thromboembolism. BMJ 1963; 5333: 777-783.

29 Blettner M, Sauerbrei W, Schlehofer B, Scheuchenpflug T, Friedenreich C. Traditional reviews, meta-analyses and pooled analyses in epidemiology. Int J Epidemiol 1999; 28: 1-9.

30 DiMarco JP, Flaker G, Waldo AL, et al. Factors affecting bleeding risk during anticoagulant therapy in patients with atrial fibrillation: observations from the Atrial Fibrillation Follow-up Investigation of Rhythm Management (AFFIRM) study. Am Heart J 2005; 149: 650-656.

31 Beyth RJ, Quinn LM, Landefeld CS. Prospective evaluation of an index for predicting the risk of major bleeding in outpatients treated with warfarin. Am J Med 1998; 105: 91-99.

32 Fihn SD, Callahan CM, Martin DC, McDonell MB, Henikoff JG, White RH. The risk for and severity of bleeding complications in elderly patients treated with warfarin. The National Consortium of Anticoagulation Clinics. Ann Intern Med 1996; 124: 970-979.

33 McMahan DA, Smith DM, Carey MA, Zhou XH. Risk of major hemorrhage for outpatients treated with warfarin. $J$ Gen Intern Med 1998; 13: 311-316.

34 Duchini A, Sessoms SL. Gastrointestinal hemorrhage in patients with systemic sclerosis and CREST syndrome. Am J Gastroenterol 1998; 93: 1453-1456.
35 O'Reilly RA, Motley CH. Racemic warfarin and trimethoprim-sulfamethoxazole interaction in humans. Ann Intern Med 1979; 91: 34-36.

36 O'Reilly RA. The stereoselective interaction of warfarin and metronidazole in man. N Engl J Med 1976; 295: 354-357.

37 Weibert RT, Lorentz SM, Townsend RJ, Cook CE, Klauber MR, Jagger PI. Effect of erythromycin in patients receiving long-term warfarin therapy. Clin Pharm 1989; 8: 210-214.

38 Israel DS, Stotka J, Rock W, et al. Effect of ciprofloxacin on the pharmacokinetics and pharmacodynamics of warfarin. Clin Infect Dis 1996; 22: 251-256.

39 Priskorn M, Sidhu JS, Larsen F, Davis JD, Khan AZ, Rolan PE. Investigation of multiple dose citalopram on the pharmacokinetics and pharmacodynamics of racemic warfarin. Br J Clin Pharmacol 1997; 44: 199-202.

40 Heimark LD, Wienkers L, Kunze K, et al. The mechanism of the interaction between amiodarone and warfarin in humans. Clin Pharmacol Ther 1992; 51: 398-407.

41 Almog S, Shafran N, Halkin H, et al. Mechanism of warfarin potentiation by amiodarone: dose - and concentration - dependent inhibition of warfarin elimination. Eur J Clin Pharmacol 1985; 28: 257-261.

42 O'Reilly RA, Trager WF, Rettie AE, Goulart DA. Interaction of amiodarone with racemic warfarin and its separated enantiomorphs in humans. Clin Pharmacol Ther 1987; 42: 290-294.

43 Murphey LM, Hood EH. Bosentan and warfarin interaction. Ann Pharmacother 2003; 37: 1028-1031.

44 Widlitz AC, Barst RJ, Horn EM. Sitaxsentan: a novel endothelin-A receptor antagonist for pulmonary arterial hypertension. Expert Rev Cardiovasc Ther 2005; 3: 985-991.

45 Ogawa A, Matsubara H, Fujio H, et al. Risk of alveolar hemorrhage in patients with primary pulmonary hypertension - anticoagulation and epoprostenol therapy. Circ J 2005; 69: 216-220.

46 Holbrook AM, Pereira JA, Labiris R, et al. Systematic overview of warfarin and its drug and food interactions. Arch Intern Med 2005; 165: 1095-1106.

47 Jones M, McEwan P, Morgan CL, Peters JR, Goodfellow J, Currie CJ. Evaluation of the pattern of treatment, level of anticoagulation control, and outcome of treatment with warfarin in patients with non-valvar atrial fibrillation: a record linkage study in a large British population. Heart 2005; 91: 472-477.

48 Reynolds MW, Fahrbach K, Hauch O, et al. Warfarin anticoagulation and outcomes in patients with atrial fibrillation: a systematic review and metaanalysis. Chest 2004; 126: 1938-1945.

49 Burton PR, Gurrin LC, Campbell MJ. Clinical significance not statistical significance: a simple Bayesian alternative to p values. J Epidemiol Community Health 1998; 52: 318-323.

50 Spiegelhalter DJ, Myles JP, Jones DR, Abrams KR. Bayesian methods in health technology assessment: a review. Health Technol Assess 2000; 4: 25-41. 